\title{
EDITORIAL
}

\section{Vessel restenosis versus "streamlining"}

\section{E Mullins}

Paediatric patients grow, therefore implanted stents must be capable of being redilated in order to accommodate this growth

$\mathrm{R}$ estenosis secondary to intimal hyperplasia within small diameter intravascular stents is a major problem in the adult population with atherosclerotic vascular disease. In contrast, most large series of stent implants in congenital lesions suggest that restenosis is rarely a problem. Schneider and colleagues, in this issue of Heart, ${ }^{1}$ point out that paediatric patients grow and that stents implanted in the paediatric population must be capable of being redilated to accommodate for the growth of the patient. Vessel growth occurs in proportion to the patient's relative somatic growth rather than simply in relation to weight gain, and growth related relative stenosis of the appropriately stented vessel is unlikely until the patient's body (and his vessels) have grown $30-50 \%{ }^{2}$

In a large series with medium to long term follow up at the Texas Children's Hospital, excessive intimal hyperplasia within stents occurred only rarely. ${ }^{3-5}$ When it does occur, there is usually some abnormality of the tissues and/or the stent implant, and the intimal hyperplasia usually does not result in a stenosis or restenosis of the vessels. Intimal hyperplasia most frequently occurs in areas where there is abnormal wall unsupported by the stent (for example, in William's syndrome); where there is elongation or "stretch" of the vessel being stented (for example, after an arterial switch with a Le Compte procedure); where there is external compression/collapse of the stent; or where an irregularly expanded stent creates significant variations in the diameter of the vessel lumen within, or in the area adjacent to, the stent. ${ }^{4}$ In these lesions, the intimal hyperplasia reduces the lumen within the stent only to the diameter of the adjacent narrowest vessel. Once the adjacent and/or stented vessels are enlarged to a uniform diameter with further dilation and additional stent implants, the stented areas do not restenose back to the smaller diameters after they are redilated. ${ }^{6}$

Correspondence to: Charles E Mullins, MD, Baylor College of Medicine, Cardiac Catheterization Laboratories, Texas Children's Hospital, 6621 Fannin Street, Houston, Texas 77030, USA; cmullins@houston.rr.com

\section{LOCALISED SHEAR STRESSES}

When an incompletely expanded, compressed or improperly implanted stent creates a discrepancy in the diameter of the vessel lumen, the different diameters in the vessel induce flow turbulence and altered localised shear stresses on the intima. This continued trauma presumably causes the excessive intimal proliferation in the localised area. Even this intimal proliferation usually does not result in a restenosis or a new stenosis of the vessel. The neointimal proliferation narrows the stented vessel only to the diameter of the smallest adjacent vessel or to the narrowest diameter remaining within the stent. In this way, the neointima "streamlines" the vessel to a uniform diameter throughout its length which, in turn, eliminates the turbulence in the area and prevents further narrowing.

The most striking examples of these phenomena are when a "waist" is left in an implanted stent and/or when a stent, at implant, is expanded to a diameter significantly larger than the adjacent vessel. In both cases, the intimal build-up reduces the resulting vessel diameter to the smallest already existing diameter within, or adjacent to, the stent. The intimal proliferation usually does not reduce the diameter further or produce further stenosis. This observation is a strong argument against overdilation at the time of implant to accommodate subsequent growth. Each vessel being stented in each patient must be considered individually, particularly looking at the aetiology of the stenosis and the size of the adjacent vessels.

Externally compressed stents are not comparable to the other mechanisms of stent intimal hyperplasia and/or stenosis in branch pulmonary arteries and represent separate indications for stent implant in the involved areas. A collapsed and/or crushed stent obviously creates a restenosis. It occurs predictably in certain areas regardless of the initial diameter of the stent at implant-although the larger the diameter of the stent becomes, the weaker the radial strength of the stent becomes.

\section{LONG SHEATHS}

Some patients in Schneider and colleagues ${ }^{1}$ series had stents delivered to the pulmonary arteries without the use of long sheaths. Few details are given on the types of balloons/stents and the technique used in these cases. The example (fig 3 ) of a stent remaining in the right ventricle for six years (out of hopefully 60-70+ years) without causing problems is not a strong argument for avoiding using a long sheath which facilitates safe, reliable stent delivery. Experience with stent delivery to the pulmonary arteries over the past 13 years suggests that the ends of rigid stents extend off the surface of the balloon as the balloon bends in the curves within the heart. This causes the exposed ends of the stent to catch on adjacent intracardiac structures as the stent is advanced or withdrawn through curved areas within the heart. ${ }^{7}$ This same mechanism actually causes the stent to catch on the inner walls of the sheath as it is advanced within a long sheath passing through a curve within the heart. 
Corinthian stents initially, and now the Genesis stents, are available pre-mounted in the USA. These stents are "flexible", essentially are "incorporated" into the balloon which fixes them very firmly to the balloon, and they have fewer sharp ends. This combination allows a reasonably safe delivery through the heart without the use of a long sheath. ${ }^{8}$ At the same time, neither of these stents, as they are presently available in the USA, can be dilated to adequate size for routine use in the main and/or proximal branch pulmonary arteries or the central arteries and veins in humans without obligating the patient to future, and more complicated, surgical intervention. Hopefully, in the future, a larger diameter of the Genesis or similar stent will be available and will be premounted on the appropriate balloons for use in central vessels. Until then and/or unless there is a similar large, securely premounted stent available outside of the USA, the long sheath delivery technique is still recommended for safe and reliable stent delivery to the central vessels.

\section{REFERENCES}

1 Schneider MBE, Zartner P, Duveneck K, et al. Various reasons for repeat dilatation of stented pulmonary arteries in paediatric patients. Heart 2002:88:505-9.

2 Morrow RW, Palmaz JC, Tio FO, et al. Re-expansion of balloon-expandable stents after growth. J Am Coll Cardiol 1993;22:2007-13.

3 O'Laughlin MP, Slack MC, Grifka RG, et al. Implantation and intermediate-term follow-up of stents in congenital heart disease. Circulation 1993;88:605-14.

4 Ing FF, Grifka RG, Nihill MR, et al. Repeat dilation of intravascular stents in congenital heart defects. Circulation 1995;92:893-7.

5 Shaffer KM, Mullins CE, Grifka RG, et al. Intravascular stents in congenital heart disease: short- and long-term results from a large single-center experience. J Am Coll Cardiol 1998;31:661-7.

6 McMahon CJ, El-Said HJ, Grifka RG, et al. Redilation of endovascular stents in congenital heart disease: factors implicated in the development of restenosis and neointimal proliferation. J Am Coll Cardiol $2001 ; 38: 521-6$

7 O'Laughlin MP, Perry SB, Lock JE, et al. Use of endovascular stents in congenital heart disease. Circulation 1991;83:1923-39.

8 Pass RH, Hsu DT, Garabedian CP, et al. Endovascular stent implantation in the pulmonary arteries of infants and children without the use of a long vascular sheath. Cathet Cardiovasc Intervent 2002;55:505-9.

\section{IMAGES IN CARDIOLOGY}

\section{Giant left ventricular pseudoaneurysm following left ventricular rupture caused by myocardial infarction}

A

66 year old man was readmitted to our hospital because of chest pain on effort.

Coronary angiography showed restenosis of the left anterior descending artery, and repeat angioplasty was successful.

One year earlier, the patient was admitted at emergency with severe chest pain. On admission, he had a pulse of 145 beats/min and a blood pressure of $60 \mathrm{~mm} \mathrm{Hg}$ with peripheral cyanosis. The ECG showed sinus tachycardia, with ST segment elevation in I, aVL, and Vl-6. Transthoracic echocardiography showed left ventricular anterior wall akinesia and a large pericardial effusion with right ventricular collapse. Subsequent coronary angiography revealed triple vessel disease with total occlusion of the left anterior descending artery. Emergency surgery was performed. The pericardial cavity was found to be full of blood clots; however, leaking of blood into the pericardial cavity had stopped, and there was a haematoma on the anterior wall of the left ventricle. Fibrin glue with a sheet of collagen was applied to the epicardial surface of the ruptured site. Left ventricular angiography, which was performed 30 days after acute myocardial infarction, showed anteroapical dyskinesis without leakage (upper panel, centre). Subsequent angioplasty of the left anterior descending artery and circumflex artery was successful.

Left ventricular angiography one year after the myocardial infarction showed a giant aneurysm on the anterior wall of the left ventricle (lower panel, centre). Transthoracic echocardiography (upper panel, right) and magnetic resonance imaging (lower panel,
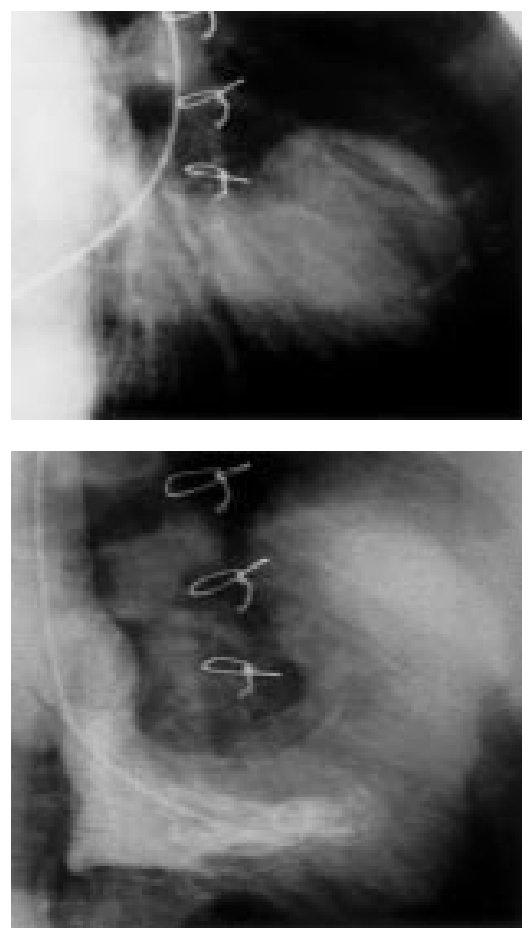

right) demonstrated a thin wall, a sack-like structure, and a mural thrombus. The pseudoaneursym was resected and the defect in the ventricular wall was closed.
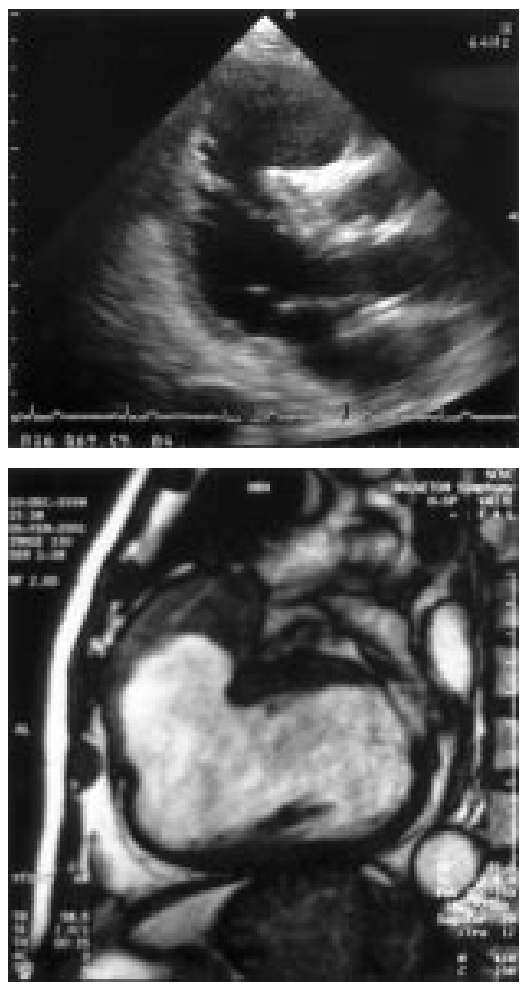

M Kanna

H Kakuchi

H Nonogi

hnonogi@hsp.ncvc.go.jp 